\title{
Dechlorination of Trichloroacetic Acid Using a Noble Metal-Free Graphene-Cu Foam Electrode via Direct Cathodic Reduction and Atomic $\mathrm{H}^{*}$
}

\author{
Ran Mao, ${ }^{\dagger \dagger}$ Ning Li, ${ }^{\dagger \dagger}$ Huachun Lan, ${ }^{\dagger}$ Xu Zhao, ${ }^{\dagger}$ Huijuan Liu, ${ }^{\dagger}$ Jiuhui $\mathrm{Qu},{ }^{*},{ }^{\dagger}$ and Meng Sun ${ }^{\dagger, \dagger}$
}

${ }^{\dagger}$ Key Laboratory of Drinking Water Science and Technology, Research Center for Eco-Environmental Sciences, Chinese Academy of Sciences, Beijing, 100085, P. R. China

${ }^{\ddagger}$ University of Chinese Academy of Sciences, Beijing, 100049, P. R. China

\section{Supporting Information}

\begin{abstract}
A three-dimensional graphene-copper (3D GR-Cu) foam electrode prepared by chemical vapor deposition method exhibited superior electrocatalytic activity toward the dechlorination of trichloroacetic acid (TCAA) as compared to the $\mathrm{Cu}$ foam electrode. The cyclic voltammetry and electrochemical impedance spectra analysis confirmed that GR accelerated the electron transfer from the cathode surface to TCAA. With the applied cathode potential of $-1.2 \mathrm{~V}$ (vs SCE), 95.3\% of TCAA $(500 \mu \mathrm{g} / \mathrm{L})$ was removed within $20 \mathrm{~min}$ at $\mathrm{pH}$ 6.8. TCAA dechlorination at the $\mathrm{Cu}$ foam electrode was enhanced at acidic $\mathrm{pH}$, while a slight $\mathrm{pH}$ effect was observed at the $\mathrm{GR}-\mathrm{Cu}$ foam electrode with a significant inhibition for $\mathrm{Cu}$ leaching. The electrocatalytic dechlorination of TCAA was accomplished via a combined stepwise and concerted pathway on both electrodes, whereas the concerted pathway was efficiently promoted on the $\mathrm{GR}-\mathrm{Cu}$ foam electrode. The direct reduction by electrons was responsible for TCAA dechlorination at $\mathrm{Cu}$ foam electrode, while at $\mathrm{GR}-\mathrm{Cu}$ foam electrode, the surface-adsorbed atomic $\mathrm{H}^{*}$ also contributed to TCAA dechlorination owing to the chemical storage of hydrogen in the GR structure. Finally, the potential applicability of GR-Cu foam was revealed by its stability in the electrocatalytic dechlorination over 25 cycles.
\end{abstract}

\section{INTRODUCTION}

Chloroacetic acids (CAAs), including mono-, di-, and trichloroacetic acids (MCAA, DCAA, and TCAA, respectively) are commonly detected disinfection byproducts in chlorinated water and known to have suspected human carcinogenicity. ${ }^{1,2}$ The U.S. Environmental Protection Agency proposed a maximum contaminant level of $60 \mu \mathrm{g} / \mathrm{L}$ for the sum of five haloacetic acids (HAAs), i.e., MCAA, DCAA, TCAA, mono(MBAA) and dibromoacetic acid (DBAA). ${ }^{3}$ Reductive dehalogenation which usually requires an addition of reducing agents such as zerovalent iron, hydrogen and sodium sulphite has been considered as an attractive option to remove HAAs in water. $^{4-7}$ For example, Hozalski et al. reported that HAAs were susceptible to reduction by zerovalent iron $\left(\mathrm{Fe}^{0}\right)$ and in compounds containing chlorine, the final product of reactions with $\mathrm{Fe}^{0}$ was MCAA. ${ }^{4}$

Application of the electrochemical reductive process in the removal of halogenated organic compounds (HOCs) is receiving growing interest. The electrochemical reduction may ensure the selective removal of halogen atoms from HOCs without producing toxic byproducts or adding any toxic chemicals. ${ }^{8,9}$ For instance, Sonoyama et al. reported an efficient electrochemical dehalogenation of several regulated trihalo- methanes using metal electrodes, while $\mathrm{Li}$ and Farrell demonstrated the reductive dechlorination of trichloroethene at iron and palladized-iron electrodes. ${ }^{10,11}$ Electrochemical reduction could be easily applied as a continuous treatment using a flow-through reactor and the pollutants present at low concentrations could be efficiently decomposed using electrodes with a large surface area.

The cathode materials play an important role in the electrochemical reduction process. ${ }^{12,13}$ Some researchers have reported that palladium $(\mathrm{Pd})$ and gold $(\mathrm{Au})$ modified electrodes showed good activities for the reduction of CAAs. ${ }^{14,15} \mathrm{Pd}$ has been explored for catalytic contaminant reduction due to the property to retain atomic $\mathrm{H}^{*}$, a highly activated intermediate hydrogen atom produced from water reduction which would serve as a strong reducing agent. ${ }^{16,17}$ However, it is desirable to design cathode materials free from noble metal catalysts for the efficient dechlorination of CAAs.

Received: October 12, 2015

Revised: March 10, 2016

Accepted: March 15, 2016

Published: March 15, 2016 
The three-dimensional graphene (3D GR) emerged as an ideal cathode material due to its large specific surface area, porous structure and excellent electrical conductivity. ${ }^{18,19}$ Compared with the 2D GR which is vulnerable to cracks, wrinkling, defective sites, and some other mechanical problems, 3D GR is structurally a well-defined material which offers mechanical robustness in all three directions. ${ }^{20} 3 \mathrm{D}$ GR has been used for oxygen reduction reaction, electrochemical sensing of dopamine and glucose, and electrodeposition of heavy metal ions. ${ }^{18,21-23}$ It can be typically fabricated by chemical vapor deposition of carbon containing gas on the $3 \mathrm{D}$ metal foam substrate. $^{24,25}$ Besides, $\mathrm{Cu}$ foam is considered as a good candidate for electrode materials in water treatment due to the low cost and extensive specific surface area. Hence, the 3D $\mathrm{GR}-\mathrm{Cu}$ foam electrode is expected to show a high electrocatalytic activity toward the dechlorination of CAAs. As far as we know, there have been no studies of such material for the treatment of HOCs. Furthermore, it is recognized that the electrochemical reduction of contaminants may occur through both direct and indirect mechanisms. ${ }^{11,15,16}$ Direct reduction may occur by electron tunneling or by the formation of a chemisorption complex for target compounds with cathode materials. ${ }^{11}$ Indirect reduction occurs via the surface-adsorbed atomic $\mathrm{H}^{*}{ }^{15,16}$ It was deduced that the indirect reduction was responsible for the dechlorination of CAAs by Pd modified electrodes. ${ }^{15}$ However, the mechanism of the electrocatalytic dechlorination of CAAs at the $\mathrm{GR}-\mathrm{Cu}$ foam cathode is unknown.

In the present work, the noble metal-free 3D GR-Cu foam electrode was fabricated through chemical vapor deposition method and its performance for TCAA dechlorination in the electrochemical reduction process was systematically investigated. The results showed that the $3 \mathrm{D}$ GR on $\mathrm{Cu}$ foam significantly facilitated the reductive transformation and promoted the concerted dechlorination pathway. The difference with a Pd-containing electrolytic system concerning the direct and indirect reduction mechanism, the feasibility of the electrochemical reductive treatment of HAAs-contaminated drinking water, and stability of the electrode in the repeated applications were also discussed.

\section{EXPERIMENTAL SECTION}

Synthesis of Electrodes. The 3D GR-Cu foam electrode was fabricated by chemical vapor deposition method in a quartz tube furnace. For the synthesis of 3D GR-Cu foam, $\mathrm{Cu}$ foam (pore density $100 \mathrm{ppi}$, thickness $1.2 \mathrm{~mm}$ ) was first ultrasonically cleaned by aqueous acetic acid solution, alcohol, and acetone, respectively, to remove oxides and organic pollutants. Then the substrate was placed in the middle of the quartz tube. Fed with mixed gas of $300 \mathrm{sccm} \mathrm{Ar}$ and $35 \mathrm{sccm} \mathrm{H}_{2}$ under about 300 mTorr, the furnace was heated to $940{ }^{\circ} \mathrm{C}$ for $2 \mathrm{~h}$. Subsequently, methane (10 sccm, purity $>99.99 \%$ ) was introduced into the system, and then cracked and deposited on $\mathrm{Cu}$ foam. The furnace was naturally cooled down to room temperature, and the 3D GR-Cu foam electrode can thus be obtained. The Pd modified carbon fiber $(\mathrm{Pd}-\mathrm{C})$ electrode was prepared via our previously reported electrodeposition method. ${ }^{26}$ The carbon fiber paper substrate (thickness $0.28 \mathrm{~mm}$, bulk density $0.44 \mathrm{~g}$ $\mathrm{cm}^{-2}$, TGP-H-090, Toray) is a graphitic sheet of the randomly arranged short carbon fibers.

Experimental Setup. All electrochemical experiments were performed with an EG\&G model 263A workstation (Princeton Applied Research, U.S.A.). A divided three-electrode system batch reactor was employed for TCAA reduction, which was separated into cathode cell $(50 \mathrm{~mL})$ and anode cell $(50 \mathrm{~mL})$ by the proton exchange membrane (Nafion-117, Du Pont). The scheme of the experimental setup is given in Figure S1 of the Supporting Information (SI). The as-prepared electrodes with a geometric surface area of $10 \mathrm{~cm}^{2}\left(2.5 \times 4 \mathrm{~cm}^{2}\right)$ served as the working electrode. A platinum wire with $72 \mathrm{~mm}$ in length and $1.5 \mathrm{~mm}$ in diameter was used as the counter electrode, and a saturated calomel electrode (SCE) was employed as the reference electrode. The system was magnetically stirred at a rate of $700 \mathrm{rpm}$. A constant potential on the cathode was controlled using the amperometric i-t technique with the electrochemical workstation throughout the reduction experiments. The conductivity of the tested tap water and $2 \mathrm{mM}$ $\mathrm{Na}_{2} \mathrm{SO}_{4}$ background electrolyte was 398 and $443 \mu \mathrm{S} / \mathrm{cm}$, respectively. The initial $\mathrm{pH}$ of the catholyte was adjusted to 6.8 by $\mathrm{H}_{2} \mathrm{SO}_{4}$ and $\mathrm{NaOH}$ before electrolysis unless otherwise specified and was not adjusted during the process. In order to investigate the effect of $\mathrm{pH}$ on the electrochemical reduction of TCAA, the initial conductivity of the catholyte at different $\mathrm{pH}$ values was adjusted to $5820 \mu \mathrm{S} / \mathrm{cm}$ using $0.5 \mathrm{M} \mathrm{Na}_{2} \mathrm{SO}_{4}$. All the experiments were carried out in triplicate. For clarity of presentation, only mean values of three experiments are presented in some cases, while standard deviations are less than $5 \%$ of the calculated mean.

The electrochemical analyses including cyclic voltammetry $(\mathrm{CV})$, electrochemical impedance spectra (EIS) and amperometric analysis were performed in an undivided conventional three-electrode cell with the same counter electrode and reference electrode as in reduction experiments. CV curves was conducted with reference to the open circuit potential. EIS was recorded by applying an $\mathrm{AC}$ voltage with $10 \mathrm{mV}$ amplitude in a frequency range $0.1-100 \mathrm{kHz}$ at open circuit voltage.

Analytical Method. All solutions were prepared using analytical grade reagents and Millipore water (specific conductivity of $18.2 \mathrm{M} \Omega$ ). The concentrations of HAA and chloride in the solution were measured using ion chromatograph (IC, ICS-2000, Dionex, Sunnyvale, CA). The detection limits of MCAA, DCAA, TCAA, MBAA, DBAA, acetic acid, and chloride are $1.5,1.0,1.8,2.5,1.7,0.6$, and $2.0 \mu \mathrm{g} / \mathrm{L}$, respectively. The concentration of $\mathrm{Cu}^{2+}$ was measured by the inductively coupled plasma optical emission spectrometer (ICP-OES, PerkinElmer Co.) with the detection limit of 10 $\mu \mathrm{g} / \mathrm{L}$.

The morphology of the electrodes was investigated using a scanning electron microscope (SEM, Zeiss SUPRA 55) equipped with an energy dispersive X-ray (EDX) analyzer. SEM image of the $\mathrm{Pd}-\mathrm{C}$ electrode is given in Figure S2. Transmission electron microscopy (TEM) images were collected on an FEI Tecnai G2 F20 S-Twin working at 200 $\mathrm{kV}$. X-ray powder diffraction (XRD) patterns of the samples were obtained with an X'Pert PRO Powder diffractometer (PANalytical Co.) with $\mathrm{Cu} \mathrm{K}_{\alpha}$ radiation. The specific surface area measurement was performed by the Brunauer-EmmettTeller (BET) method. Raman spectra were recorded on a Bruker Senterra Raman spectrometer and microscope through a $20 \mathrm{X}$ objective lens using a $20 \mathrm{~mW}$ and a $514 \mathrm{~nm}$ laser excitation. X-ray photoelectron spectra (XPS) was performed using a PHI Quantera SXM (PHI-5300/ESCA, ULVAC-PHI, Inc.). The electron spin resonance (ESR) signals of radicals spin trapped by spin-trap reagent 5,5'-dimethyl-1-pirroline- $N$ oxide (DMPO, purchased from Sigma Chemical Co.) were detected on a Bruker model ESR 300E spectrometer equipped 

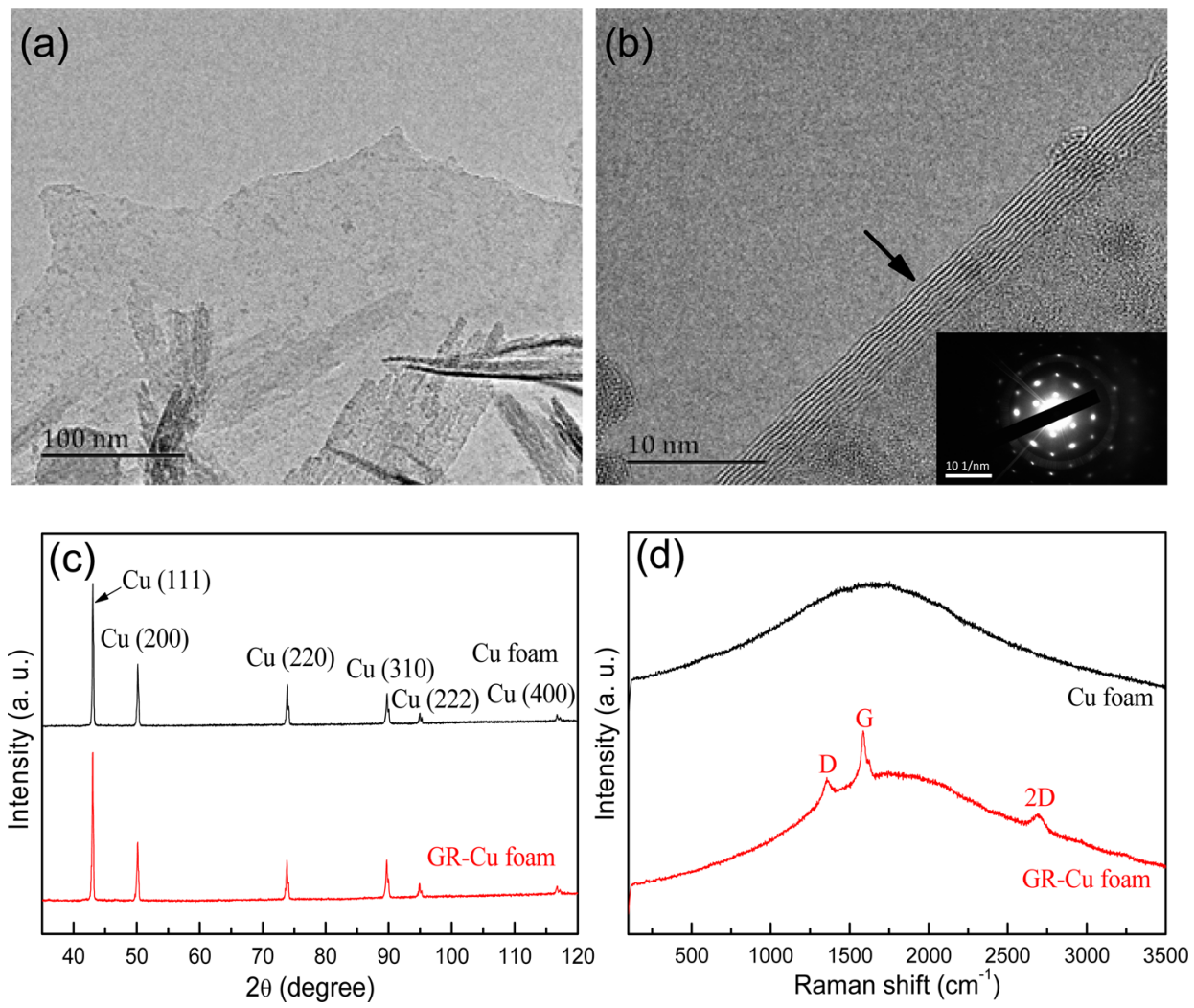

Figure 1. (a) Low- and (b) high-magnification TEM images of GR, where a SAED pattern recorded from the center of the domains is shown in the inset, (c) XRD patterns, and (d) Raman spectra of the $\mathrm{Cu}$ foam and GR-Cu foam electrodes.

with a quanta-Ray Nd:YAG laser system as the irradiation source.

\section{RESULTS AND DISCUSSION}

Characterization of the electrodes. The low- and highmagnification TEM images of the GR transferred onto the TEM grids are shown in Figure $1 \mathrm{a}$ and $\mathrm{b}$. The GR with 10 layers (indicated by the arrow) can be identified clearly through the folded edge, along with the selected area electron diffraction (SAED) pattern shown in inset, revealing the typical hexagonal crystalline nature of GR. It is found that GR sheets are composed of graphite layers and most of them have 8-10 layers. The EDX mapping analysis provides clear information about the uniform distribution of GR throughout the whole structure of $\mathrm{Cu}$ foam (Figure S3). XRD patterns of the $\mathrm{Cu}$ foam and $\mathrm{GR}-\mathrm{Cu}$ foam electrodes are recorded in Figure 1c, where diffraction peaks assigned to (111), (200), (220), and (310) of metallic $\mathrm{Cu}$ are observed. On the basis of the analysis of Raman spectroscopy, the two prominent bands observed in the GR-Cu foam around 1586 and $2682 \mathrm{~cm}^{-1}$ are assigned to the $\mathrm{G}$ and $2 \mathrm{D}$ bands of carbon, respectively, proving that GR were successfully synthesized on the $\mathrm{Cu}$ foam substrate (Figure 1d). The $I_{2 \mathrm{D}} / I_{\mathrm{G}}$ intensity ratio was known to strongly correlate with the number of GR layers. ${ }^{27}$ This value is low in the synthesized $\mathrm{GR}-\mathrm{Cu}$ foam, which is consistent with the TEM observation of the multilayered GR. The weak defect-related D peak reflects the high quality of the 3D-GR.

Performance of the GR-Cu Foam Electrode for Dechlorination of CAAs. First, the electrocatalytic dechlorination of TCAA at the $\mathrm{Cu}$ foam and $\mathrm{GR}-\mathrm{Cu}$ foam electrodes was performed under the same experimental conditions. The removal efficiency of TCAA through $\mathrm{GR}-\mathrm{Cu}$ foam electrode achieves $95.2 \%$ at $20 \mathrm{~min}$; meanwhile, the value is $48.9 \%$ for $\mathrm{Cu}$ foam electrode (Figure 2). It is also shown that the

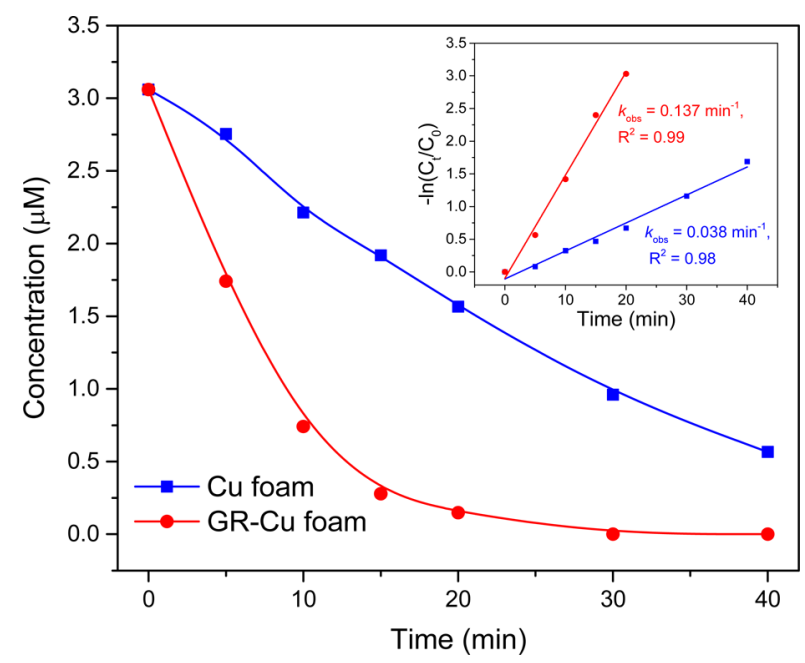

Figure 2. Electrocatalytic dechlorination of TCAA at the $\mathrm{Cu}$ foam and $\mathrm{GR}-\mathrm{Cu}$ foam electrodes $\left([\mathrm{TCAA}]_{0}=3.06 \mu \mathrm{M}\right.$, applied potential $=$ $-1.2 \mathrm{~V}$ vs SCE, $2 \mathrm{mM} \mathrm{Na}_{2} \mathrm{SO}_{4}$, initial $\left.\mathrm{pH}=6.8\right)$.

dechlorination of TCAA follows a pseudo-first order kinetic model, which is expressed as $-\operatorname{Ln}\left(C_{t} / C_{0}\right)=k t+b$, where $t$ is the reaction time $(\mathrm{min}), k$ is the reaction rate constant $\left(\mathrm{min}^{-1}\right)$, $b$ is a constant, and $C_{\mathrm{t}}$ and $C_{0}$ are the TCAA concentrations $(\mu \mathrm{M})$ at times of $t=t$ and $t=0$, respectively. The observed reaction rate constants $\left(k_{\text {obs }}\right)$ of TCAA through $\mathrm{Cu}$ foam and $\mathrm{GR}-\mathrm{Cu}$ foam cathode are found to be 0.038 and $0.137 \mathrm{~min}^{-1}$, 
respectively. The results indicate that the $\mathrm{GR}-\mathrm{Cu}$ foam electrode shows a much higher electrocatalytic activity in contrast to $\mathrm{Cu}$ foam electrode for TCAA dechlorination.

The electrocatalytic activities of the two cathodes toward TCAA dechlorination were further characterized by CV scan and EIS. When TCAA was added, the peak current of -0.95 $\mathrm{mA}$ appeared at the potential of $-1.19 \mathrm{~V}$ on the $\mathrm{Cu}$ foam (Figure 3a). By contrast, on the $\mathrm{GR}-\mathrm{Cu}$ foam, the peak current
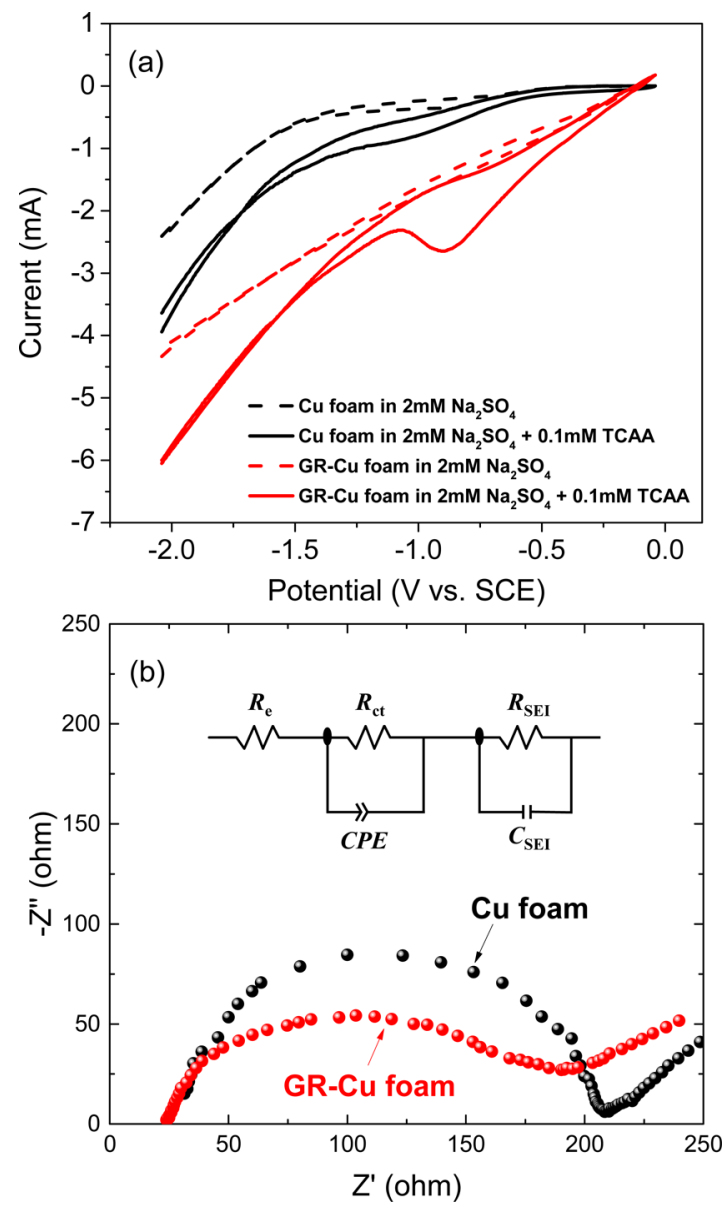

Figure 3. (a) CV spectra of TCAA reduction on $\mathrm{Cu}$ foam and $\mathrm{GR}-\mathrm{Cu}$ foam (scan rate: $10 \mathrm{mV} / \mathrm{s}$ ), (b) Nyquist diagrams obtained at $\mathrm{Cu}$ foam and GR-Cu foam in $2 \mathrm{mM} \mathrm{Na}_{2} \mathrm{SO}_{4}$ and $0.1 \mathrm{mM}$ TCAA. Inset is the equivalent electrical circuit used to fit the EIS data $\left(R_{\mathrm{e}}\right.$ is the electrolyte resistance, $R_{\mathrm{ct}}$ is the charge-transfer resistance, CPE is the constant phase-angle element, and $R_{\mathrm{SEI}}$ and $C_{\mathrm{SEI}}$ are the pseudocapacitance and resistance of solid/electrolyte interface, respectively).

was significantly decreased to be $-2.64 \mathrm{~mA}$ at a less negative potential around $-0.89 \mathrm{~V}$. The reduction peaks can be attributed to the electron transfer from cathodes to TCAA since they did not appear in the absence of TCAA. This result indicates that TCAA reduction is more kinetically favorable at $\mathrm{GR}-\mathrm{Cu}$ foam cathode. In EIS, the arc radius on the Nyquist plot corresponds to the electron transfer limiting process. ${ }^{28}$ When GR was loaded, the size of the arc radius was reduced, revealing that GR decreased the interface impedance and accelerated the electron transfer (Figure $3 \mathrm{~b}$ ). On the basis of the results, it was speculated that $3 \mathrm{D}$ GR in the hybrid materials set up a fairly conductive network, which may facilitate the charge-transfer and mass-transfer processes. Due to its unique electronic structure, the GR works as a highly conductive matrix for quickly providing electrons which might be favorable for TCAA dechlorination. Additionally, according to the results of the BET test, the specific surface area of the GR-Cu foam $\left(3.3844 \mathrm{~m}^{2} \mathrm{~g}^{-1}\right)$ is larger than that of the $\mathrm{Cu}$ foam $\left(1.3229 \mathrm{~m}^{2}\right.$ $\left.\mathrm{g}^{-1}\right)$. The increased surface area may also lead to enhanced reactions at the reactive sites, thus facilitating the electrocatalytic dechlorination of TCAA.

Meantime, the $k_{\text {obs }}$ of TCAA, DCAA, and MCAA by the Cu foam and $\mathrm{GR}-\mathrm{Cu}$ foam electrodes are illustrated in Figure S4. The GR-Cu foam electrode shows higher rate constants of the CAAs dechlorination, which are 3-6 times larger than those at the $\mathrm{Cu}$ foam electrode. Besides, Table S1 suggests an increased dechlorination rate with the chlorination degree (TCAA > DCAA > MCAA). It was recognized that the strong electron withdrawing ability of the chlorine atom caused the carbon center electron deficient, which was more amenable to electrophilic attack. ${ }^{29,30}$ Thus, the highly chlorinated CAAs would be more prone to be reduced during the dechlorination process, which is consistent with previous studies. ${ }^{31,32}$

Effect of Cathode Potential and Initial TCAA Concentration. The electrochemical reduction of TCAA on the GR$\mathrm{Cu}$ foam electrode at different cathode potentials was investigated, and the results are presented in Figure 4a. Nearly no loss of TCAA is observed at the applied potential of -0.3 and $-0.5 \mathrm{~V}$ (vs SCE) within $40 \mathrm{~min} .89 .2 \%$ removal of TCAA is attained with the rate constant of $0.063 \mathrm{~min}^{-1}$ at $-0.7 \mathrm{~V}$,
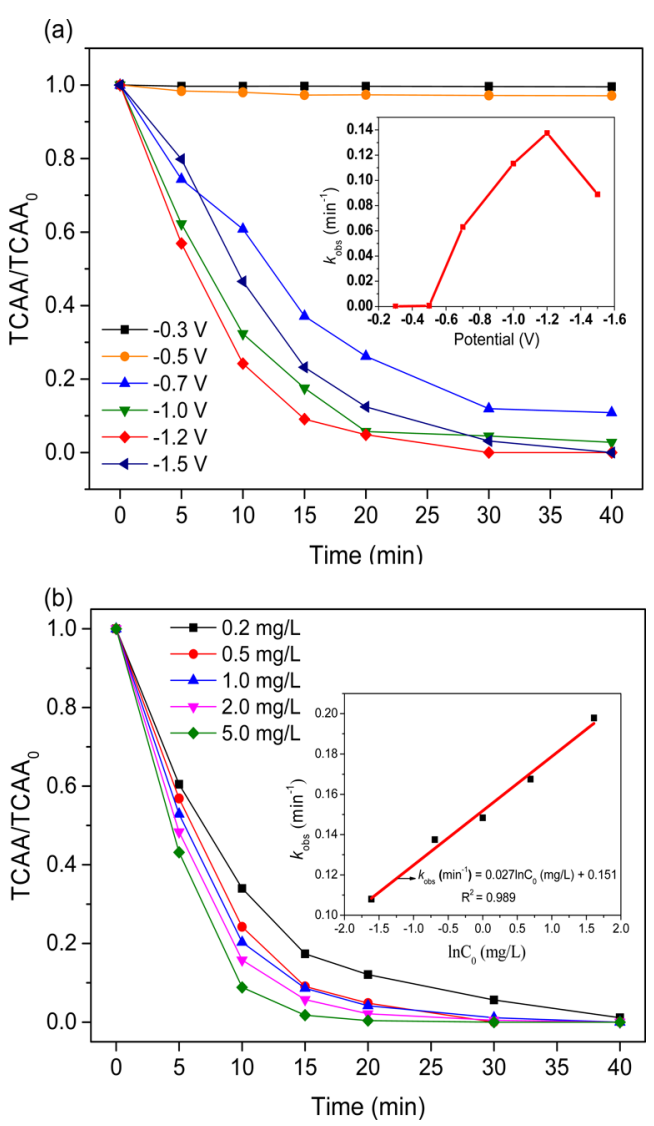

Figure 4. (a) Effect of cathode potential on TCAA reduction at the $\mathrm{GR}-\mathrm{Cu}$ foam electrode $\left([\mathrm{TCAA}]_{0}=3.06 \mu \mathrm{M}, 2 \mathrm{mM} \mathrm{Na}_{2} \mathrm{SO}_{4}\right.$, initial $\mathrm{pH}=6.8)$ and (b) effect of initial TCAA concentration on TCAA reduction at the $\mathrm{GR}-\mathrm{Cu}$ foam electrode (applied potential $=-1.2 \mathrm{~V}$ vs $\mathrm{SCE}, 2 \mathrm{mM} \mathrm{Na}_{2} \mathrm{SO}_{4}$, initial $\mathrm{pH}=6.8$ ). 

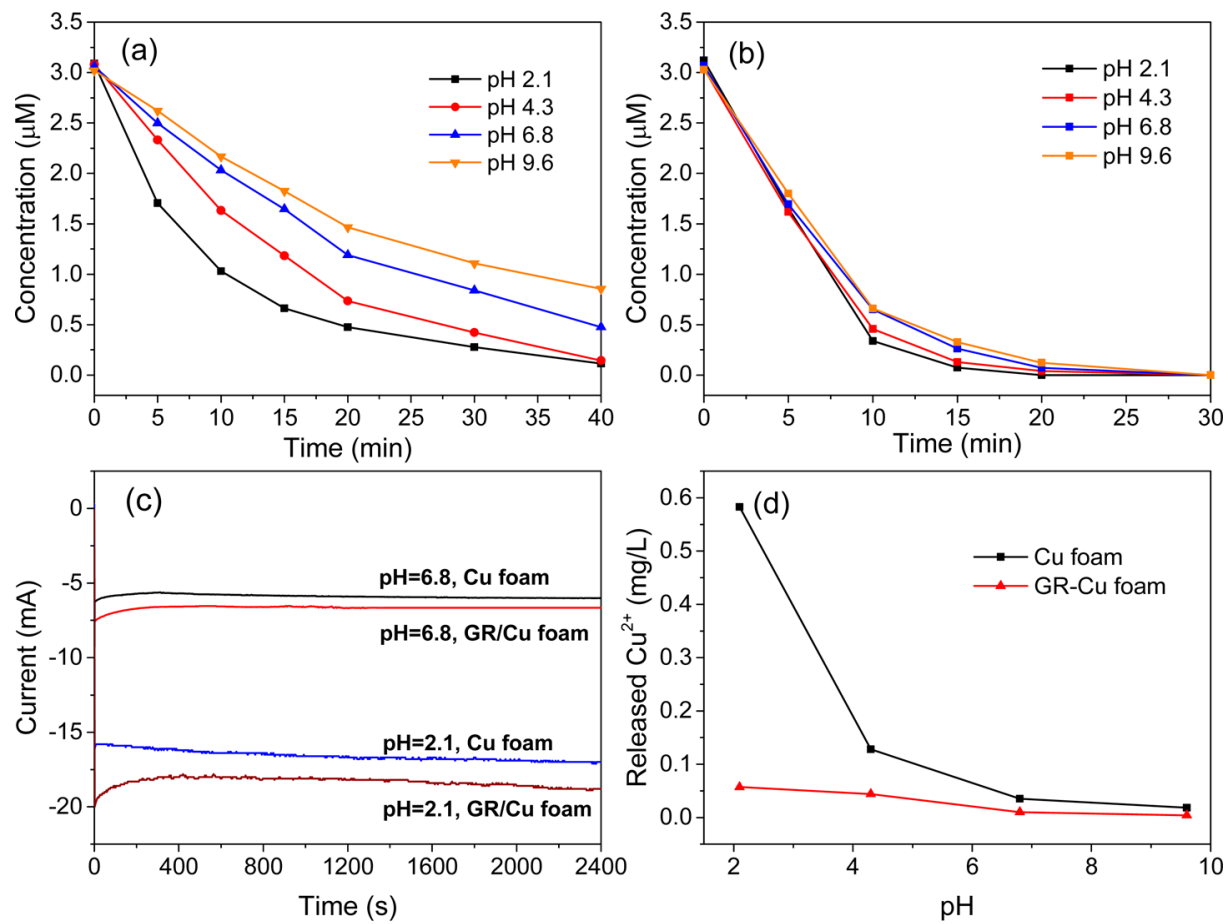

Figure 5. Effect of initial $\mathrm{pH}$ on TCAA reduction at the (a) $\mathrm{Cu}$ foam and (b) GR-Cu foam electrode, (c) chronoamperometric profiles of the electrodes at $\mathrm{pH} 2.1$ and 6.8 , and $(\mathrm{d})$ the released $\mathrm{Cu}^{2+}$ after reaction at different $\mathrm{pH}\left([\mathrm{TCAA}]_{0}=3.06 \mu \mathrm{M}\right.$, applied potential $=-1.2 \mathrm{~V}$ vs SCE$)$. The initial conductivity of the catholyte at different $\mathrm{pH}$ values is kept constant.

which is more positive than the cathodic peak potential in the $\mathrm{CV}$ scan $(-0.89 \mathrm{~V})$. It has been recognized that the characteristic shape of the $\mathrm{CV}$ is a result of the potentialdependent changes in the surface concentrations of the redox system and the simultaneous diffusion processes. ${ }^{33}$ The cathodic peak potential is reached when all of the substrate exposed to the surface of an electrode has been reduced. ${ }^{34}$ Accordingly, TCAA in solution can undergo electrochemical conversion before the reduction current peak during the cathodic scan. The obtained result of the reduction experiment is in accord with the $\mathrm{CV}$ behavior of the $\mathrm{GR}-\mathrm{Cu}$ foam electrode. Similar phenomenons can be found in previous studies. ${ }^{35-37}$ The reaction rate then gradually rises to 0.113 and $0.137 \mathrm{~min}^{-1}$ when the applied bias potential is decreased to -1.0 and $-1.2 \mathrm{~V}$, respectively. However, further decrease of the potential to $-1.5 \mathrm{~V}$ results in a decrease in the reaction rate. This can be attributed to the numerous hydrogen bubbles evolved at $-1.5 \mathrm{~V}$ which would influence the electron conduction at the electrode surface. ${ }^{15}$ The result also indicates that the role of TCAA adsorption is negligible and the electrocatalytic reduction is the primary process for TCAA removal. The change of $\mathrm{pH}$ during the electrochemical process at various cathode potentials is provided in Figure S5. When decreasing potentials from -0.7 to $-1.5 \mathrm{~V}$, the difference in the final $\mathrm{pH}$ value is less than 0.5 . The $\mathrm{pH}$ effect on the dechlorination would be analyzed subsequently.

Initial concentration of the target TCAA is an important factor for the removal efficiency during electrocatalytic process. ${ }^{9}$ The reduction rate of TCAA at the GR-Cu foam electrode increases successively with increasing the initial TCAA concentration (Figure $4 \mathrm{~b}$ ). The $k_{\mathrm{obs}}$ versus logarithm of TCAA concentration curve shows a certain linear relationship $\left(R^{2}=0.989\right)$, which probably can be used for the prediction of $k_{\mathrm{obs}}$ at the GR-Cu foam electrode for a given
TCAA concentration within a specific range. Combined with the effect of cathode potential and initial TCAA concentration on the reduction rate of TCAA, it could be deduced that electron transfer and TCAA diffusion were simultaneously responsible for controlling the electrochemical reduction process under tested conditions.

Effect of Solution $\mathrm{pH}$ and Dissolved Oxygen. A comparison of TCAA dechlorination at $\mathrm{Cu}$ foam and GR$\mathrm{Cu}$ foam electrodes with various $\mathrm{pH}$ values under the same initial conductivity was performed. TCAA dechlorination is promoted with decreasing $\mathrm{pH}$ from 9.6 to 2.1 at the $\mathrm{Cu}$ foam electrode (Figure 5a), whereas it is only slightly enhanced with a decrease of $\mathrm{pH}$ at the $\mathrm{GR}-\mathrm{Cu}$ foam electrode (Figure $5 \mathrm{~b}$ ). The corresponding kinetic constants at the two electrodes are provided in Figure S6. The electrons coupled with $\mathrm{H}^{+}$are considered to take part in the dechlorination process on the cathode surface. $^{29}$ Therefore, acidic solution facilitates the dechlorination of TCAA on $\mathrm{Cu}$ foam electrode as it is an $\mathrm{H}^{+}$ consumption process. Meanwhile, the lowered electrostatic repulsion between the negatively charged TCAA and cathode due to the shielding effect of protons at lower $\mathrm{pH}$ could also contribute to the higher dechlorination efficiency. As for the $\mathrm{GR}-\mathrm{Cu}$ foam electrode, the weaker $\mathrm{pH}$ effect reflects that the electrocatalytic dechlorination of TCAA with the electrode can be performed under a wide $\mathrm{pH}$ range. The hydrolysis effect on the removal can be excluded as the measured concentrations of TCAA, DCAA, and MCAA are identical to the initial concentrations in the $\mathrm{pH}$ range from 2.1 to 11.2 without applying any electrochemical potential (Figure S7).

The chronoamperometry profiles show that the electroreduction currents on $\mathrm{GR}-\mathrm{Cu}$ foam electrode are higher than those on $\mathrm{Cu}$ foam electrode in both neutral and acidic solutions (Figure $5 \mathrm{c}$ ). The higher currents on GR-Cu foam may be due to the conductive multilayered $\mathrm{GR}$ in the porous and 
interconnected structure, which is advantageous for the efficient diffusion and transport of electrons or intermediates. This result is in agreement with its behavior in the electrocatalytic reduction. Additionally, the current at $\mathrm{pH} 2.1$ on either electrode is higher than that at $\mathrm{pH} 6.8$, which is probably attributed to the enhanced hydrogen evolution reaction at $\mathrm{pH}$ 2.1. Furthermore, the leaching of $\mathrm{Cu}$ after reaction at different $\mathrm{pH}$ under the same conductivity is presented in Figure 5d. The concentration of released $\mathrm{Cu}^{2+}$ with the $\mathrm{Cu}$ foam electrode is determined to be 0.583 and $0.128 \mathrm{mg} / \mathrm{L}$ at $\mathrm{pH} 2.1$ and 4.3 , respectively. While for the $\mathrm{GR}-\mathrm{Cu}$ foam electrode, the concentration of $\mathrm{Cu}^{2+}$ under the same conditions is significantly reduced to 0.057 and $0.044 \mathrm{mg} / \mathrm{L}$, respectively, suggesting a significant inhibition for $\mathrm{Cu}$ dissolution by the $\mathrm{GR}-\mathrm{Cu}$ foam electrode.

Dissolved oxygen may compete with TCAA for the reaction sites at the cathode. By purging the solution with $\mathrm{N}_{2}$, the concentration of dissolved oxygen was reduced from 7.98 to $0.56 \mathrm{mg} / \mathrm{L}$. The reduction rate at the $\mathrm{GR}-\mathrm{Cu}$ foam electrode is observed to be 0.269 and $0.137 \mathrm{~min}^{-1}$ with and without $\mathrm{N}_{2}$ sparging, respectively (Figure S8). It was reported by Xie et al. that dissolved oxygen may compete with trichloroethylene for both the electrons and atomic $\mathrm{H}^{*}$ on the cathode surface, thus suppressing trichloroethylene reduction. ${ }^{16}$ In this study, the enhancement of the reaction rate in the presence of $\mathrm{N}_{2}$ indicates the competition effects with oxygen for reactive sites on the cathode.

Reaction Pathway and Mechanism. The intermediates and final products generated from the electrocatalytic dechlorination of TCAA on $\mathrm{Cu}$ foam and $\mathrm{GR}-\mathrm{Cu}$ foam electrodes are compared in Figure 6. TCAA is degraded within the first $90 \mathrm{~min}$ at the $\mathrm{Cu}$ foam electrode, with the concomitant rise of DCAA as the major product (Figure 6a). While at the GR-Cu foam electrode, the completely dechlorinated product acetic acid is efficiently generated as TCAA is rapidly consumed within the first $20 \mathrm{~min}$ (Figure $6 \mathrm{~b}$ ). The higher generation of chloride at the GR-Cu foam electrode is consistent with its higher production of acetic acid. Further, accompanied by the sequential dechlorination of TCAA, MCAA, and acetic acid are immediately detected in both reaction systems, indicating the direct dechlorination pathways from TCAA to MCAA or acetic acid and from DCAA to acetic acid. ${ }^{7}$ Thus, the electrocatalytic dechlorination of TCAA may be implemented via a combined stepwise and concerted pathway as depicted in Figure S9. The respective rate constants of the dechlorination of CAAs on both electrodes are obtained by fitting the kinetic data (see details in Section S1 and Figure S10), and the results are summarized in Table S2. Notably, for TCAA the ratio of the rate constants of the concerted pathways $\left(k_{2}+k_{3}\right)$ to that of the stepwise pathway $\left(k_{1}\right)$ is 0.13 and 0.26 for $\mathrm{Cu}$ foam and $\mathrm{GR}-\mathrm{Cu}$ foam, respectively, indicating that the TCAA dechlorination on both electrodes is mainly controlled by the stepwise pathway. As for DCAA, the ratio of the rate constant of the concerted pathway $\left(k_{5}\right)$ to that of the stepwise pathway $\left(k_{4}\right)$ is 0.29 and 1.19 for $\mathrm{Cu}$ foam and $\mathrm{GR}-\mathrm{Cu}$ foam, respectively, reflecting that the concerted pathway is predominant on the $\mathrm{GR}-\mathrm{Cu}$ foam electrode. On the basis of the above results, it can be concluded that the concerted pathway is efficiently promoted on the GR$\mathrm{Cu}$ foam electrode as compared to the $\mathrm{Cu}$ foam electrode, especially for the DCAA produced by the dechlorination of TCAA.

Regarding the electrochemical reduction process, two mechanisms that have been proposed involve direct electron

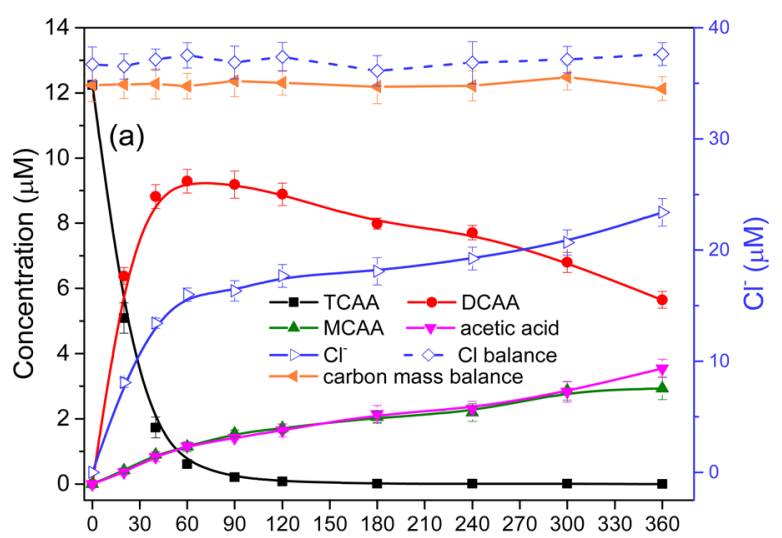

Time (min)

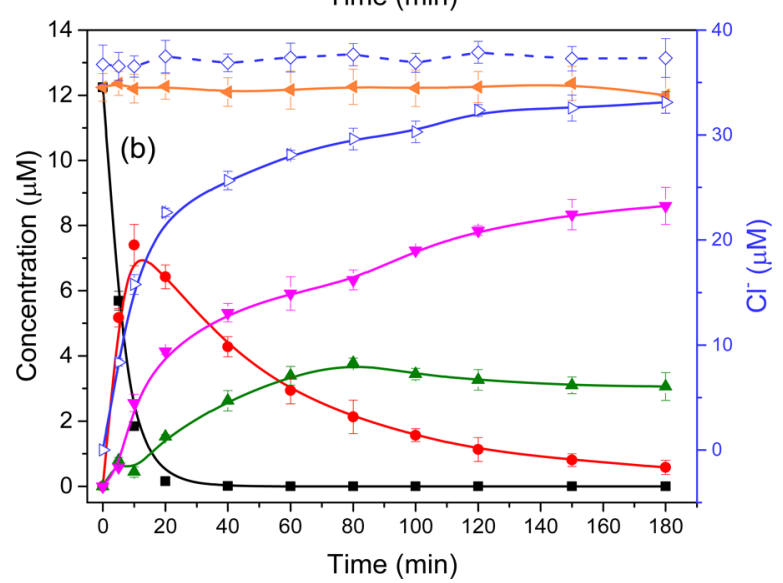

Figure 6. Intermediates and final products of reductive dechlorination of TCAA through (a) $\mathrm{Cu}$ foam electrode and (b) $\mathrm{GR}-\mathrm{Cu}$ foam electrode $\left([\mathrm{TCAA}]_{0}=12.24 \mu \mathrm{M}\right.$, applied potential $=-1.2 \mathrm{~V}$ vs SCE, 2 $\mathrm{mM} \mathrm{Na} \mathrm{SO}_{4}$, initial $\left.\mathrm{pH}=6.8\right)$. The dashed line represents the observed chloride mass balance.

transfer and indirect reduction via atomic $\mathrm{H}^{*} \cdot{ }^{11,15,16}$ Tertiary butanol $(t-\mathrm{BuOH})$ which can scavenge the hydrogen atoms was used to identify the role of atomic $\mathrm{H}^{*}$ for TCAA dechlorination at different electrodes. ${ }^{38,39}$ The efficiency of TCAA dechlorination at the $\mathrm{Cu}$ foam electrode remains nearly constant with the addition of incremental levels of $t-\mathrm{BuOH}$ from 0 to $5.0 \mathrm{mM}$ (Figure $7 \mathrm{a}$ ). While on the $\mathrm{GR}-\mathrm{Cu}$ foam electrode, the dechlorination rate decreases gradually when $t-\mathrm{BuOH}$ is increased from 0 to $1.0 \mathrm{mM}$, and then keeps constant with further increasing $t$ - $\mathrm{BuOH}$ amount (Figure $7 \mathrm{~b}$ ). In the presence of $5.0 \mathrm{mM} t-\mathrm{BuOH}$, up to $96.8 \%$ of TCAA can still be removed within $20 \mathrm{~min}$ at the $\mathrm{GR}-\mathrm{Cu}$ foam electrode. However, at the $\mathrm{Pd}-\mathrm{C}$ electrode (Pd loading amount $0.75 \mathrm{mg} / \mathrm{cm}^{2}, S_{\mathrm{BET}} 1.2906$ $\left.\mathrm{m}^{2} \mathrm{~g}^{-1}\right)$, the reduction rate of TCAA decreases obviously with the increase of the $t-\mathrm{BuOH}$ concentration (Figure $7 \mathrm{c}$ ). Furthermore, the atomic $\mathrm{H}^{*}$ involved in the electroreduction process was detected by the ESR spin trapping, which was first reported in our previous research. ${ }^{40}$ As shown in Figure $7 d$, nine characteristic peaks of DMPO-H are observed at all of the three electrodes; no such signals are detected in the black electrolyte. The peak intensity for the GR-Cu foam electrode is nearly identical to that of the $\mathrm{Pd}-\mathrm{C}$ electrode, which is larger than that of the $\mathrm{Cu}$ foam electrode.

The discharge of water through the Volmer step with the formation of surface-adsorbed atomic $\mathrm{H}^{*}$, the electrochemical desorption (Heyrovsky step) and the recombination of the atomic $\mathrm{H}^{*}$ (Tafel step) are generally accepted as the steps of 

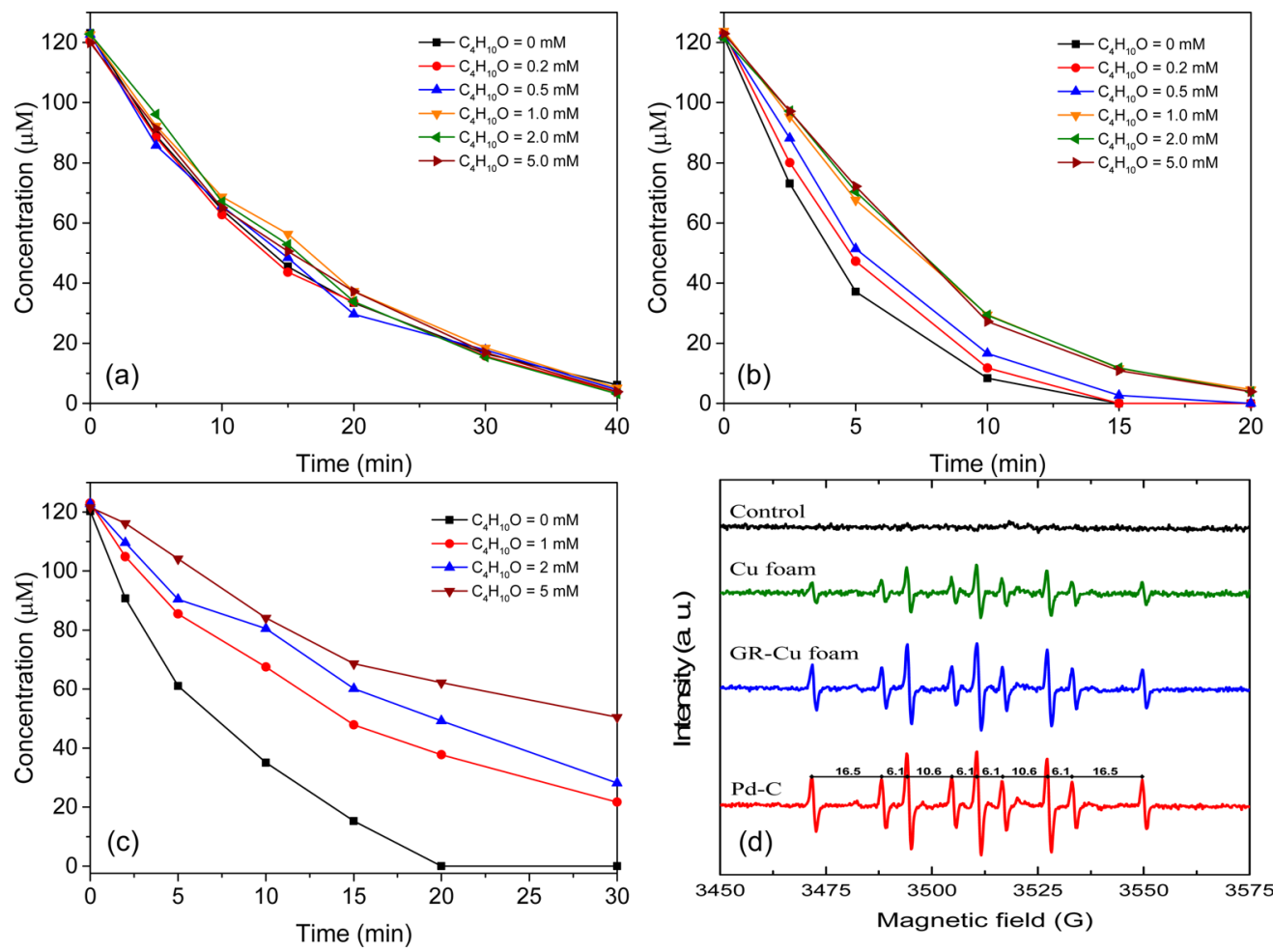

Figure 7. Removal of TCAA by (a) Cu foam electrode, (b) GR-Cu foam electrode and (c) $\mathrm{Pd}-\mathrm{C}$ electrode in the electroreduction process with various $\mathrm{C}_{4} \mathrm{H}_{10} \mathrm{O}$ concentrations $\left([\mathrm{TCAA}]_{0}=122.4 \mu \mathrm{M}\right.$, applied potential $=-1.2 \mathrm{~V}$ vs SCE, $2 \mathrm{mM} \mathrm{Na}_{2} \mathrm{SO}_{4}$, initial $\left.\mathrm{pH}=6.8\right)$, (d) DMPO spintrapping ESR spectra with $\mathrm{Cu}$ foam, GR-Cu foam and $\mathrm{Pd}-\mathrm{C}$ electrodes (applied potential $=-1.2 \mathrm{~V}$ vs SCE).

the kinetic mechanism of the hydrogen evolution reaction, as given by ${ }^{41}$

$$
\begin{aligned}
& \mathrm{H}_{2} \mathrm{O}+\mathrm{e}^{-} \leftrightarrow \mathrm{H}^{*}+\mathrm{OH}^{-} \text {(Volmer) } \\
& \mathrm{H}_{2} \mathrm{O}+\mathrm{H}^{*}+\mathrm{e}^{-} \leftrightarrow \mathrm{H}_{2(\mathrm{~g})}+\mathrm{OH}^{-} \text {(Heyrovsky) } \\
& 2 \mathrm{H}^{*} \leftrightarrow \mathrm{H}_{2(\mathrm{~g})}(\text { Tafel })
\end{aligned}
$$

Atomic $\mathrm{H}^{*}$ would accordingly be generated first by Volmer mechanism, which can explain the DMPO-H adducts observed at the three electrodes. However, in the absence of normally required noble metal catalysts (e.g., $\mathrm{Pd}$ and $\mathrm{Ag}$ ) for hydrogen storage, atomic $\mathrm{H}^{*}$ would turn to $\mathrm{H}_{2}$ quickly by Heyrovsky and Tafel routes during the TCAA reduction process. ${ }^{16,42-44}$ Thus, the role of atomic $\mathrm{H}^{*}$ in the dechlorination of TCAA at the barely $\mathrm{Cu}$ foam electrode can be ignored and the direct electron transfer is responsible for TCAA dechlorination. In contrast, Pd is well-known to have the unique property of adsorbing large amounts of nascent $\mathrm{H}^{*}$ via the $\mathrm{Pd}-\mathrm{H}$ bonds based on multiple $\sigma$-bonding between the hydrogen atoms and the $\mathrm{d}$ orbitals of the Pd atoms. ${ }^{45,46}$ Even if $\mathrm{H}_{2}$ molecules are formed, they would be readily dissociated on the $\mathrm{Pd}$ surface. ${ }^{47}$ Therefore, the electrocatalytic dechlorination of TCAA at the $\mathrm{Pd}-\mathrm{C}$ electrode mainly proceeds via the indirect $\mathrm{H}^{*}$ reduction due to the ability of $\mathrm{Pd}$ to maintain a high surface concentration of atomic $\mathrm{H}^{*}$. It has been shown that hydrogen can also be adsorbed on GR and the reaction of GR with hydrogen atoms generates $\mathrm{sp}^{3} \mathrm{C}-\mathrm{H}$ bonds on the basal plane. ${ }^{48-50}$ The hydrogenation of GR was considered to be more feasible with multilayer GR than that with single-layer $\mathrm{GR}^{51}$ At the GR-Cu foam electrode, a certain amount of surface-adsorbed atomic $\mathrm{H}^{*}$ derived from such chemical storage of hydrogen in the GR nanostructure turns to be active species, which is in part responsible for the effective
TCAA dechlorination. However, atomic $\mathrm{H}^{*}$ plays a relatively minor role and the primary dechlorination of TCAA at the $\mathrm{GR}-\mathrm{Cu}$ foam electrode is achieved by the direct mechanism.

Potential Application. In the current work, the efficient and rapid dechlorination of chlorinated compounds was achieved in the electrochemical reduction process using a 3D $\mathrm{GR}-\mathrm{Cu}$ foam cathode. The use of expensive Pd or Au catalyst was avoided. Treatment of HAAs-contaminated tap water by the electroreduction process with the $\mathrm{GR}-\mathrm{Cu}$ foam cathode was conducted to check its applicability in a realistic water matrix. The water quality of Beijing tap water was provided in Table S3. The initial concentration of HAAs was adjusted to $120 \mu \mathrm{g} / \mathrm{L}$, including $20 \mu \mathrm{g} / \mathrm{L}$ for DBAA, $50 \mu \mathrm{g} / \mathrm{L}$ for DCAA and TCAA, respectively. As presented in Figure 8a, HAAs are reduced below $60 \mu \mathrm{g} / \mathrm{L}$ at $15 \mathrm{~min}$, indicating that the electrochemical dechlorination of HAAs has the potential for application to drinking water treatment in some specific cases because of its rapid reduction rate. The 25-cycle dechlorination reaction experiment shows a first increased and then nearly constant activity at the $\mathrm{Cu}$ foam and $\mathrm{GR}-\mathrm{Cu}$ foam electrodes (Figure $8 \mathrm{~b}$ ). Further insights on the XPS spectrum of $\mathrm{Cu} 2 \mathrm{p}_{3 / 2}$, ${ }_{1 / 2}$ (Figure $\mathrm{S} 11$ ), and $\mathrm{C} 1 \mathrm{~s}$ (Figure $\mathrm{S} 12$ ) indicate that $\mathrm{CuO}$ is partly reduced to $\mathrm{Cu}^{0}$ by cathodic current on the two electrodes, and the GR maintains stability during the dechlorination reaction. XRD and Raman spectra further demonstrate the stability of the electrodes (Figure S13). Thus, the electrocatalytic activities could be first enhanced due to the decrement of $\mathrm{CuO}$ content by cathodic polarization and then maintain nearly constant with durations. The energy consumption for the $\mathrm{GR}-\mathrm{Cu}$ foam electrode is calculated to be 0.067 against $0.159 \mathrm{kWh} \mathrm{g}^{-1}$ TCAA for the $\mathrm{Cu}$ foam electrode at $-1.2 \mathrm{~V}$ (Figure S14 and Table S4). Because of its high effectiveness and stability, low cost, and environmental 

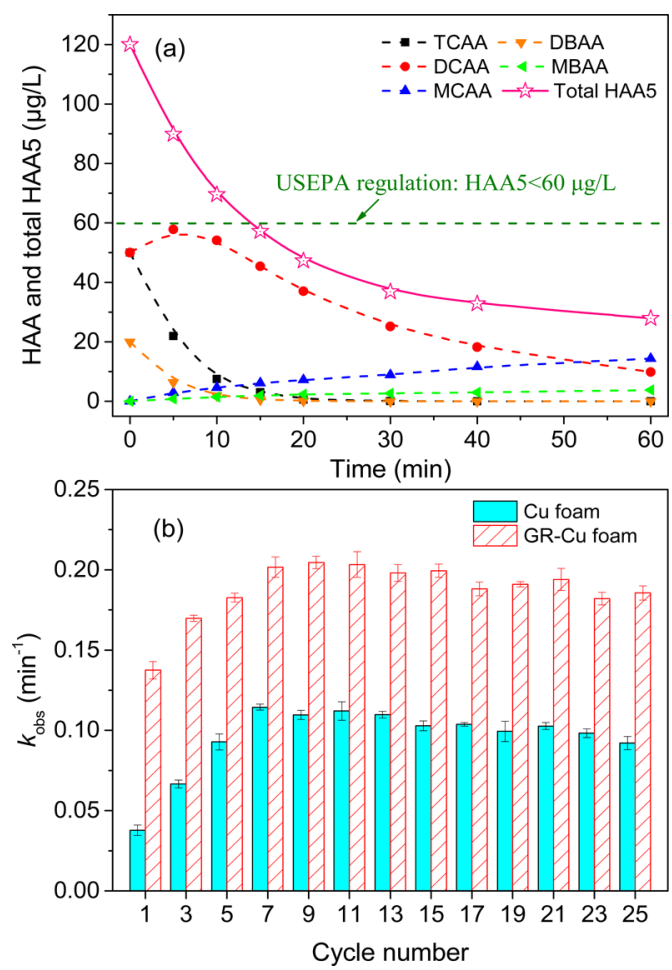

Figure 8. (a) HAAs concentration in tap water during the electrochemical reductive process with the $\mathrm{GR}-\mathrm{Cu}$ foam electrode $\left([\mathrm{TCAA}]_{0}=[\mathrm{DCAA}]_{0}=50 \mu \mathrm{g} / \mathrm{L},[\mathrm{DBAA}]_{0}=20 \mu \mathrm{g} / \mathrm{L}\right.$, applied potential $=-1.2 \mathrm{~V}$ vs $\mathrm{SCE}$ ) and (b) 25-cycle dechlorination reaction of TCAA by $\mathrm{Cu}$ foam and $\mathrm{GR}-\mathrm{Cu}$ foam electrodes $\left([\mathrm{TCAA}]_{0}=3.06\right.$ $\mu \mathrm{M}$, applied potential $=-1.2 \mathrm{~V}$ vs SCE, $2 \mathrm{mM} \mathrm{Na}_{2} \mathrm{SO}_{4}$, initial $\mathrm{pH}=$ $6.8)$.

friendliness, the 3D GR-Cu foam electrode would play a beneficial role as a promising cathode in the electroreduction process for efficient removal of HOCs in water, especially for a point-of-use drinking water treatment.

\section{ASSOCIATED CONTENT}

\section{S Supporting Information}

Experimental setup; SEM and EDX mapping images of electrodes, fitted rate constants, change of $\mathrm{pH}$ at different cathode potentials, hydrolysis test, effect of dissolved oxygen, reaction pathway, and fitting of the kinetic data; water quality of the Beijing tap water, XPS, XRD, and Raman spectra of the electrodes before and after the dechlorination, and energy cost analysis. The Supporting Information is available free of charge on the ACS Publications website at DOI: 10.1021/ acs.est.5b05006.

(PDF)

\section{AUTHOR INFORMATION}

\section{Corresponding Author}

*Tel.: +86-10-62849151; fax: +86-10-62923558; e-mail: jhqu@ rcees.ac.cn (J.Q.).

\section{Notes}

The authors declare no competing financial interest.

\section{ACKNOWLEDGMENTS}

This work was supported by National Natural Science Foundation of China (Nos. 51290282, 51478455, 21377148) and National High Technology Research and Development
Program of China (No. 2012AA062604). The authors sincerely thank Prof. Yongfeng Li, Zhiqiang Tu, and Xiuwen Xu at China University of Petroleum, Ms. Li Yan and Ms. Fanglan Geng at RCEES, and Prof. Shourong Zheng and Dr. Juan Zhou at Nanjing University for their generous help in electrode preparation, TEM measurement, and kinetic data analysis.

\section{REFERENCES}

(1) Christman, R. F.; Norwood, D. L.; Millington, D. S.; Johnson, J. D.; Stevens, A. A. Identity and yields of major halogenated products of aquatic fulvic acid chlorination. Environ. Sci. Technol. 1983, 17, 625628.

(2) Hong, Y.; Song, H.; Karanfil, T. Formation of haloacetic acids from dissolved organic matter fractions during chloramination. Water Res. 2013, 47, 1147-1155.

(3) Pontius, F. W. Complying with future water regulations. J.Am. Water Works Assoc. 1999, 91, 46-58.

(4) Hozalski, R. M.; Zhang, L.; Arnold, W. A. Reduction of haloacetic acids by $\mathrm{Fe}^{0}$ : implications for treatment and fate. Environ. Sci. Technol. 2001, 35, 2258-2263.

(5) Croue, J. P.; Reckhow, D. A. Destruction of chlorination byproducts with sulfite. Environ. Sci. Technol. 1989, 23, 1412-1419.

(6) Nutt, M. O.; Hughes, J. B.; Wong, M. S. Designing Pd-on-Au bimetallic nanoparticle catalysts for trichloroethene hydrodechlorination. Environ. Sci. Technol. 2005, 39, 1346-1353.

(7) Zhou, J.; Han, Y. X.; Wang, W. J.; Xu, Z. Y.; Wan, H. Q.; Yin, D. Q.; Zheng, S. R.; Zhu, D. Q. Reductive removal of chloroacetic acids by catalytic hydrodechlorination over $\mathrm{Pd} / \mathrm{ZrO}_{2}$ catalysts. Appl. Catal., B 2013, 134-135, 222-230.

(8) Korshin, G. V.; Jensen, M. D. Electrochemical reduction of haloacetic acids and exploration of their removal by electrochemical treatment. Electrochim. Acta 2001, 47, 747-751.

(9) Li, Y. P.; Cao, H. B.; Zhang, Y. Reductive dehalogenation of haloacetic acids by hemoglobin-loaded carbon nanotube electrode. Water Res. 2007, 41, 197-205.

(10) Sonoyama, N.; Seike, S.; Sueoka, T.; Sakata, T. Electrochemical decomposition of $\mathrm{ppb}$ level trihalomethane in tap water. J. Appl. Electrochem. 2003, 33, 1049-1055.

(11) Li, T.; Farrell, J. Reductive dechlorination of trichloroethene and carbon tetrachloride using iron and palladized-iron cathodes. Environ. Sci. Technol. 2000, 34, 173-179.

(12) Sun, C.; Baig, S. A.; Lou, Z. M.; Zhu, J.; Wang, Z. X.; Li, X.; Wu, J. H.; Zhang, Y. F.; Xu, X. H. Electrocatalytic dechlorination of 2, 4dichlorophenoxyacetic acid using nanosized titanium nitride doped palladium/nickel foam electrodes in aqueous solutions. Appl. Catal., B 2014, 158-159, 38-47.

(13) Mao, X. H.; Ciblak, A.; Amiri, M.; Alshawabkeh, A. N. Redox control for electrochemical dechlorination of trichloroethylene in bicarbonate aqueous media. Environ. Sci. Technol. 2011, 45, 65176523.

(14) Altamar, L.; Fernandez, L.; Borras, C.; Mostany, J.; Carrero, H.; Scharifker, B. Electroreduction of chloroacetic acids (mono-, di- and tri-) at polyNi (II)-tetrasulfonated phthalocyanine gold modified electrode. Sens. Actuators, B 2010, 146, 103-110.

(15) Li, A. Z.; Zhao, X.; Hou, Y. N.; Liu, H. J.; Wu, L. Y.; Qu, J. H. The electrocatalytic dechlorination of chloroacetic acids at electrodeposited Pd/Fe-modified carbon paper electrode. Appl. Catal., B 2012, 111-112, 628-635.

(16) Xie, W. J.; Yuan, S. H.; Mao, X. H.; Hu, W.; Liao, P.; Tong, M.; Alshawabkeh, A. N. Electrocatalytic activity of Pd-loaded $\mathrm{Ti} / \mathrm{TiO}_{2}$ nanotubes cathode for TCE reduction in groundwater. Water Res. 2013, 47, 3573-3582.

(17) Lee, J. Y.; Lee, J. G.; Lee, S. H.; Seo, M.; Piao, L.; Bae, J. H.; Lim, S. Y.; Park, Y. J.; Chung, T. D. Hydrogen-atom-mediated electrochemistry. Nat. Commun. 2013, 4, 2766-2733.

(18) Li, W. W.; Gao, S.; Wu, L. Q.; Qiu, S. Q.; Guo, Y. F.; Geng, X. M.; Chen, M. L.; Liao, S. T.; Zhu, C.; Gong, Y. P.; Long, M. S.; Xu, J. B.; Wei, X. F.; Sun, M. T.; Liu, L. W. High-density three-dimension 
graphene macroscopic objects for high-capacity removal of heavy metal ions. Sci. Rep. 2013, 3, 2125-2130.

(19) Wang, L.; Sofer, Z.; Ambrosi, A.; Šimek, P.; Pumera, M. 3Dgraphene for electrocatalysis of oxygen reduction reaction: Increasing number of layers increases the catalytic effect. Electrochem. Commun. 2014, 46, 148-151.

(20) Pumera, M. Voltammetry of carbon nanotubes and graphenes: excitement, disappointment, and reality. Chem. Rec. 2012, 12, 201213.

(21) Wu, Z. S.; Yang, S. B.; Sun, Y.; Parvez, K.; Feng, X. L.; Mullen, $\mathrm{K} .3 \mathrm{D}$ nitrogen-doped graphene aerogel-supported $\mathrm{Fe}_{3} \mathrm{O}_{4}$ nanoparticles as efficient electrocatalysts for the oxygen reduction reaction. J. Am. Chem. Soc. 2012, 134, 9082-9085.

(22) Dong, X. C.; Cao, Y. F.; Wang, J.; Chan-Park, M. B.; Wang, L. H.; Huang, W.; Chen, P. Hybrid structure of zinc oxide nanorods and three dimensional graphene foam for supercapacitor and electrochemical sensor applications. RSC Adv. 2012, 2, 4364-4369.

(23) Xiao, X. Y.; Michael, J. R.; Beechem, T.; McDonald, A.; Rodriguez, M.; Brumbach, M. T.; Lambert, T. N.; Washburn, C. M.; Wang, J.; Brozik, S. M.; Wheeler, D. R.; Burckel, D. B.; Polsky, R. Three dimensional nickel-graphene core-shell electrodes. J. Mater. Chem. 2012, 22, 23749-23754.

(24) Chen, Z.; Ren, W.; Gao, L.; Liu, B.; Pei, S.; Cheng, H. M. Threedimensional flexible and conductive interconnected graphene networks grown by chemical vapor deposition. Nat. Mater. 2011, 10, 424-428.

(25) Dong, X.-C.; Xu, H.; Wang, X.-W.; Huang, Y.-X.; Chan-Park, M. B.; Zhang, H.; Wang, L.-H.; Huang, W.; Chen, P. 3D graphene-cobalt oxide electrode for high-performance supercapacitor and enzymeless glucose detection. ACS Nano 2012, 6, 3206-3213.

(26) Mao, R.; Zhao, X.; Lan, H. C.; Liu, H. J.; Qu, J. H. Efficient electrochemical reduction of bromate by a $\mathrm{Pd} / \mathrm{rGO} / \mathrm{CFP}$ electrode with low applied potentials. Appl. Catal., B 2014, 160-161, 179-187.

(27) Reina, A.; Jia, X. T.; Ho, J.; Nezich, D.; Son, H. B.; Bulovic, V. Large area, few-layer graphene films on arbitrary substrates by chemical vapor deposition. Nano Lett. 2009, 9, 30-35.

(28) Sugimoto, W.; Iwata, H.; Yokoshima, K.; Murakami, Y.; Takasu, Y. Proton and electron conductivity in hydrous ruthenium oxides evaluated by electrochemical impedance spectroscopy: The origin of large capacitance. J. Phys. Chem. B 2005, 109, 7330-7338.

(29) Wang, X. Y.; Ning, P.; Liu, H. L.; Ma, J. Dechlorination of chloroacetic acids by $\mathrm{Pd} / \mathrm{Fe}$ nanoparticles: Effect of drying method on metallic activity and the parameter optimization. Appl. Catal., B 2010, 94, 55-63.

(30) Scherer, M. M.; Balko, B. A.; Gallagher, D. A.; Tratnyek, P. G. Correlation analysis of rate constants for dechlorination by zero-valent iron. Environ. Sci. Technol. 1998, 32, 3026-3033.

(31) Mackenzie, K.; Frenzel, H.; Kopinke, F.-D. Hydrodehalogenation of halogenated hydrocarbons in water with Pd catalysts: reaction rates and surface competition. Appl. Catal., B 2006, 63, 161-167.

(32) Muftikian, R.; Fernando, Q.; Korte, N. A method for the rapid dechlorination of low molecular weight chlorinated hydrocarbons in water. Water Res. 1995, 29, 2434-2439.

(33) Heinze, J. Cyclic voltammetry-"Electrochemical spectroscopy". New analytical methods. Angew. Chem., Int. Ed. Engl. 1984, 23, 831847.

(34) Kissinger, P. T.; Heineman, W. R. Cyclic voltammetry. J. Chem. Educ. 1983, 60, 702-706.

(35) Chaplin, B. P.; Schrader, G.; Farrell, J. Electrochemical oxidation of n-nitrosodimethylamine with boron-doped diamond film electrodes. Environ. Sci. Technol. 2009, 43, 8302-8307.

(36) Guo, H. L.; Wang, X. F.; Qian, Q. Y.; Wang, F. B.; Xia, X. H. A green approach to the synthesis of graphene nanosheets. ACS Nano 2009, 3, 2653-2659.

(37) Hu, Y.; Jin, J.; Wu, P.; Zhang, H.; Cai, C. Graphene-gold nanostructure composites fabricated by electrodeposition and their electrocatalytic activity toward the oxygen reduction and glucose oxidation. Electrochim. Acta 2010, 56, 491-500.
(38) Buxton, G. V.; Greenstock, C. L.; Helman, W. P.; Ross, A. B. Critical review of rate constants for reactions of hydrated electrons, hydrogen atoms and hydroxyl radicals in aqueous solution. J. Phys. Chem. Ref. Data 1988, 17, 513-886.

(39) Mezyk, S. P.; Cooper, W. J.; Madden, K. P.; Bartels, D. M. Free radical destruction of $\mathrm{N}$-nitrosodimethylamine in water. Environ. Sci. Technol. 2004, 38, 3161-3167.

(40) Mao, R.; Zhao, X.; Lan, H. C.; Liu, H. J.; Qu, J. H. Graphenemodified $\mathrm{Pd} / \mathrm{C}$ cathode and $\mathrm{Pd} / \mathrm{GAC}$ particles for enhanced electrocatalytic removal of bromate in a continuous three-dimensional electrochemical reactor. Water Res. 2015, 77, 1-12.

(41) Gennero de Chialvo, M. R.; Chialvo, A. C. Kinetics of hydrogen evolution reaction with Frumkin adsorption: re-examination of the Volmer-Heyrovsky and Volmer-Tafel routes. Electrochim. Acta 1998, $44,841-851$.

(42) Radjenovic, J.; Farre, M. J.; Mu, Y.; Gernjak, W.; Keller, J. Reductive electrochemical remediation of emerging and regulated disinfection byproducts. Water Res. 2012, 46, 1705-1714.

(43) Cheng, I. F.; Fernando, Q.; Korte, N. Electrochemical dechlorination of 4-chlorophenol to phenol. Environ. Sci. Technol. 1997, 31, 1074-1078.

(44) Knitt, L. E.; Shapley, J. R.; Strathmann, T. J. Rapid metalcatalyzed hydrodehalogenation of iodinated X-ray contrast media. Environ. Sci. Technol. 2008, 42, 577-583.

(45) Conner, W. C.; Falconer, J. L. Spillover in heterogeneous catalysis. Chem. Rev. 1995, 95, 759-788.

(46) Chaplin, B. P.; Reinhard, M.; Schneider, W. F.; Schüth, C.; Shapley, J. R.; Strathmann, T. J.; Werth, C. J. Critical review of Pdbased catalytic treatment of priority contaminants in water. Environ. Sci. Technol. 2012, 46, 11469-11470.

(47) Lee, J.; Shim, W.; Noh, J.-S.; Lee, W. Design rules for nanogapbased hydrogen gas sensors. ChemPhysChem 2012, 13, 1395-1403.

(48) Dimitrakakis, G. K.; Tylianakis, E.; Froudakis, G. E. Pillared graphene: A new 3-D network nanostructure for enhanced hydrogen storage. Nano Lett. 2008, 8, 3166-3170.

(49) Park, N.; Hong, S.; Kim, G.; Jhi, S.-H. Computational study on hydrogen storage characteristics of covalent-bonded graphenes. J. Am. Chem. Soc. 2007, 129, 8999-9003.

(50) Pumera, M. Graphene-based nanomaterials for energy storage. Energy Environ. Sci. 2011, 4, 668-674.

(51) Subrahmanyam, K. S.; Kumar, P.; Maitra, U.; Govindaraj, A.; Hembram, K. P. S. S.; Waghmare, U. V.; Rao, C. N. R. Chemical storage of hydrogen in few-layer graphene. Proc. Natl. Acad. Sci. U. S. A. 2011, 108, 2674-2677. 